\title{
PRÁTICAS LEITORAS DE ALUNOS DO SEGUNDO CICLO DO ENSINO FUNDAMENTAL
}

Cristiane ÂNGELO

UEM

Renilson MENEGASSI

UEM

Resumo: O presente trabalho trata da análise de questionários de leitura aplicados a 202 alunos da série final de segundo ciclo do ensino fundamental (quarta série) pertencentes a nove escolas localizadas no município de Irati-PR, sendo duas na área central da cidade, três em bairros próximos e quatro na zona rural. O objetivo geral foi diagnosticar a qualidade de leitura desses alunos atendidos pelas redes pública e particular do município. Os resultados demonstram o predomínio nas escolas da concepção de leitura como extração de significados do texto. Assim, os alunos tendem a renunciar às palavras próprias, adquiridas em suas experiências histórico-sócio-culturais, valorizando apenas o que o texto lhes apresenta.

Palavras-chave: leitura; ensino fundamental; quarta série.

Abstract: Questionnaires on reading applied to 202 students of Fourth Year in the lower primary school in nine schools in the municipality of Irati-PR, Brazil, are analyzed. Whereas two schools lie in downtown Irati, three are in its districts and four in the rural área. Current research's main aim was to diagnose the reading quality of these students taken care of public and private district schools net. The results reveal the predominance in the schools of the conception of reading as an extraction of the meanings of the text. Consequently, the students refrain from using their own words and expressions acquired in their historical, social and cultural experiences, considering only what the text actually presents.

Key-words: reading; diagnosis; schooling, Fourth Year.

Resumen: Este trabajo trata de un análisis de encuestas de lectura aplicadas a 202 alumnos del último curso de enseñanza primaria (cuarto curso), pertenecientes a nueve escuelas ubicadas en el municipio de 
Irati-PR, dos de las escuelas ubicadas en el área central de la ciudad, tres en barrios cercanos y cuatro en el área rural. La investigación tuvo como objetivo diagnosticar la calidad de lectura de esos alumnos atendidos por escuelas de enseñanza pública y privada del municipio. Los resultados demuestran que la concepción de lectura predominante en las escuelas es la de lectura como extracción de significados del texto. Así, los alumnos suelen rechazar las propias palabras, adquiridas en sus experiencias históricas y socioculturales, valorando tan solamente lo que les presenta el texto.

Palabras clave: lectura; ensenanza primaria; cuarto afio.

\section{Introdução}

Ao partir do pressuposto de que a leitura é um processo interativo entre leitor e texto, este artigo pretende apontar as principais características de leitura de alunos do final do segundo ciclo do Ensino Fundamental - $4^{\text {a }}$ série, a fim de que os órgãos competentes e os professores possam (re)definir prioridades de ensino. Para tanto, foi realizada uma análise de questionários de leitura aplicados a 202 alunos, pertencentes a nove escolas do município de Irati-Paraná, sendo duas localizadas na área central da cidade, três em bairros próximos ao centro e quatro no interior, abrangendo, assim, todo o território do município.

Este artigo encontra-se estruturado da seguinte forma: na primeira parte, demonstra-se que o modo de pensar o ler está associado ao desenvolvimento dos estudos sobre a linguagem; na sequência, demonstra-se a metodologia que orientou o trabalho de campo; na terceira parte, apresentam-se os resultados da análise.

\section{Leitura: do estruturalismo aos estudos do discurso}

O desenvolvimento de teorias sobre leitura está atrelado ao desenvolvimento da própria Linguística. A princípio, o objeto de investigação eram as unidades isoladas da língua; com o desenvolvimento das pesquisas das ciências da linguagem, o foco foi alterando-se até chegar à concepção de texto como unidade comunicativa e às condições sócio-históricas-ideológicas em que o texto é produzido, proposta em voga na atualidade. 
Kato (1986) apresenta, ainda que sumariamente, um panorama das tendências que exerceram influência no modo de conceber a leitura ao longo do século XX. Na linguística estruturalista, pensa-se a leitura como decodificação, palavra que na teoria da leitura quer dizer passar do código escrito para o código oral. Acredita-se que, uma vez realizada essa decodificação, de palavra em palavra, chegase sem problemas ao conteúdo.

Uma segunda concepção surge quando se constata a importância do conhecimento lexical do leitor para identificar a palavra. O leitor é considerado, a partir daí, como "antecipador da palavra que vai ler" (KATO, 1986, p.61).

$\mathrm{Na}$ linguística gerativista, a preocupação desloca-se para o nível sentencial. Os investigadores começam a perceber que não basta o leitor conhecer previamente a palavra, mas que é preciso considerar o contexto linguístico (sentencial) onde ocorre a palavra.

Entretanto, logo se observa que o contexto de estudar o texto a partir da sentença apenas não parece suficiente. Surge, então, a Linguística Textual, que se opõe às correntes anteriores ao tomar como objeto particular de investigação não mais a palavra ou a frase, mas sim, o texto -unidade básica de manifestação da linguagem. A preocupação volta-se para os princípios de constituição do texto (o que faz com que o texto seja um texto). Além disso, dentro dessa perspectiva textual, outra corrente surgiu, considerando que havia necessidade de se levar em conta as informações textuais e extratextuais que interferem na construção do significado. Diz-se construção e não mais decodificação, porque se compreende que o significado não está nos dados linguísticos, mas provém do leitor, de suas experiências, da sua capacidade de predizer e confirmar as hipóteses.

Por sua vez, a Pragmática aparece sublinhando a leitura como um processo de interação entre o leitor e o texto. Nesse processo, o leitor, através das informações explícitas e implícitas, procura obter os objetivos e as intenções do autor. Então, diferentemente de outras tendências linguísticas preocupadas exclusivamente com que o texto diz, a Pragmática atenta-se ao por que o autor diz o que diz.

Cabe salientar, ainda, a influência da Análise do Discurso no modo de pensar a leitura, pois ela traz para o bojo das discussões a historicidade na constituição do discurso. Nega a intencionalidade, já 
que, para ela, é a ideologia que determina a configuração dos sentidos. Portanto, a pergunta que deve ser feita é "Como o texto significa?".

Numa perspectiva psicolingiiística, Sole (2003) constata que, embora as formulações teóricas que atribuem um papel importante ao leitor e a seu conhecimento prévio estejam ganhando destaque, as posturas que dão ênfase ao texto e que vêem a leitura como um processo de identificação de sinais gráficos ainda persistem. Dessa forma, "coexistem", no domínio das pesquisas e da prática escolar, diferentes perspectivas de leitura: a perspectiva do texto, a perspectiva do leitor, a perspectiva da interação e a perspectiva discursiva.

$\mathrm{Na}$ primeira, o texto é o senhor absoluto dos sentidos, ou seja, é visto como um objeto completo em si mesmo, cujos elementos, ao serem decodificados, dão o seu sentido, independentemente do leitor das circunstâncias em que foi produzido (cf. GOUGH apud KLEIMAN, 1989). A perspectiva do leitor apresenta o leitor como a fonte dos sentidos, demonstrando que a compreensão começa na mente do leitor que toma o texto somente para confirmar expectativas e hipóteses (GOODMAN, 1987; SMITH, 1999). Ambas podem ser consideradas concepções restritas de leitura, uma vez que confiam exageradamente em uma das fontes de informação -texto ou leitor em detrimento da outra.

A perspectiva interacionista pretende conciliar as duas anteriores, observando que os sentidos são construídos na interação entre texto e leitor (KLEIMAN, 2000). Observa-se que essa abordagem ainda mostra limitações, pois as condições de produção ainda são ignoradas; também o texto continua sendo autoridade que predetermina a gama de leituras possíveis.

$\mathrm{Na}$ perspectiva discursiva, ressalta-se o momento históricosocial como responsável por constituir a significação do texto (ORLANDI, 2000). Portanto, considera-se que os sentidos não estão apenas nas palavras, mas na relação com o que está fora do texto, nas condições em que eles são produzidos, trazendo-se para o texto o mundo do leitor.

Neste trabalho, assume-se a perspectiva interacionistadiscursiva, que resulta da articulação entre a perspectiva interacionista e a perspectiva discursiva. Esta considera o leitor como um participante ativo do processo da leitura, visto que ele confronta o seu saber com outros saberes presentes no texto de forma clara ou subentendida; é 
capaz de perceber que todo texto se constrói a partir de determinadas condições de produção, ou seja, os sentidos dependem do momento em que o texto foi produzido, do local em que foi divulgado e das contribuições do sujeito leitor.

\section{Percurso metodológico da pesquisa}

Para diagnosticar a competência leitora de alunos na série final do segundo ciclo ( $4^{a}$ série), optou-se pela pesquisa qualitativointerpretativa, com ênfase na abordagem etnográfica, necessitando para isso percorrer os caminhos da coleta de registros que se evidenciam, por sua natureza, em material quantitativo. A opção por esse tipo de pesquisa deve-se ao fato de ela permitir ao pesquisador envolver-se com a realidade da sala de aula, entender o que se sucede nesse espaço quanto ao ensino-aprendizagem da leitura, problematizar e buscar respostas que elucidem eventuais dúvidas e dificuldades e, conseqúentemente, contribuir com uma reflexão crítica acerca da qualidade de leitura dos alunos do ensino fundamental atendidos no município de Irati-PR como mostra representativa do Centro-Oeste do Paraná.

Participaram da pesquisa 202 alunos da série final do segundo ciclo do ensino fundamental pertencentes a nove escolas localizadas no município assim discriminadas: ZUC1 e ZUC2 (escolas públicas de zona urbana centro); ZUB1 e ZUB2 (escolas públicas de zona urbana bairro); EP (escola particular) e ZR1, ZR2, ZR3 e ZR4 (escolas públicas de zona rural).

A coleta de informações foi realizada no segundo semestre de 2004. A pesquisadora dirigiu-se às escolas, conversou com os professores e alunos acerca dos objetivos da pesquisa e solicitou que os alunos realizassem a leitura de um texto e respondessem a um questionário referente ao que fora lido. Foram necessárias três visitas a cada escola para que a coleta pudesse ser concluída, com três aplicações distintas.

Para as atividades de leitura foram utilizados textos de circulação social - "Viciadas em comer os próprios ovos" (resposta à carta de leitor/Revista Globo Rural); "Pode me chamar de Centro Cultural" (propaganda da Associação Nacional de Editores de Revistas /Revista Época); "O tabaco consome dinheiro público" (campanha 
de conscientização realizada pelo Ministério da Saúde/Revista Época) - além dos questionários de leitura. Nesses questionários, buscava-se investigar se o aluno extraía informações explícitas do texto, identificava o objetivo e o destinatário do texto; conseguia explicar partes do texto; relacionava o texto num todo coerente; estabelecia relações entre frases e idéias do texto; buscava outros discursos sociais, além daqueles que marcam a posição social do leitor, para sustentar as respostas.

\section{Resultados das análises}

Nesta seção, tecem-se reflexões sobre o desempenho dos alunos nas tarefas propostas. Inicialmente, apresenta-se um breve comentário geral sobre a performance dos alunos. A seguir, abordase a interferência do fator "contexto social" em suas leituras. Finalmente, levanta-se uma série de explicações para as dificuldades de leitura dos alunos do $2^{\circ}$ ciclo do Ensino Fundamental.

É possível verificar que, em vários momentos, os alunos desejam revelar, emitir um ponto de vista crítico referente ao conteúdo do texto ou a uma dada realidade, embora muitas vezes essa não seja correspondente ao ponto de vista explicitado no texto ou ao que foi perguntado. Citam-se, como exemplos, as respostas à questão: "Explique com suas palavras o título do texto", referente ao texto "O tabaco consome dinheiro público":

"que você trabalha e paga impostos e o dinheiro vai para a prefeitura" (ZR3);

"ele consome dinheiro público ou seja ele da prejuizo para o brazil ele consome o dinheiro que épara arrumar ruas, estradas, calsadas, asfaltas" (ZUC2);

"por que a prefeitura não quer que parem de vender tabaco porque metade do dinheiro vai na prefeitura" (ZUC2).

Outro exemplo consiste na resposta à pergunta "Qual o objetivo do texto?", referente ao texto "Viciadas em comer os próprios ovos":

"fala que a galinha tem um bico e bebe os ovos mas não carece cortar o bico dá pra pegar um fogo e queima não tem prerigo" (ZR3) 
Nos primeiros exemplos, os alunos adotam uma atitude reflexiva, pois questionam a realidade social ao criticar o pagamento de taxas à prefeitura e a falta de recursos para cuidar dos bens e serviços públicos. No último, o aluno trava uma polêmica com o texto, pois discorda das informações apresentadas e propõe outro argumento, amparando-se em sua vivência. Diante disso, percebe-se que esses sujeitos vêem na leitura uma possibilidade de constituir-se, de revelarse, de mostrar desejos e visões de mundo.

Verifica-se, ainda, que os alunos mostram marcas de condições sócio-históricas. Assim, eles não apelam apenas para o vocabulário do texto, mas também para o seu próprio "arquivo de palavras e expressões", o qual revela sinais do lugar social e histórico e de experiências em leituras anteriores. No entender de Dell'Isola (1996, p.72), o sujeito leitor e o texto se constróem em um contexto social. Ao anunciar, o sujeito produtor "revela marcas de sua individualidade, produto de suas características psicológicas e socioculturais. O leitor apropria-se da linguagem, num momento individual, deixando o registro de seu lugar social no texto lido", conforme mostram os seguintes exemplos:

Texto: Viciadas em comer os próprios ovos Pergunta: Se o criador de galinhas deseja obter ovos e já tentou de todos os modos eliminar o vício das aves, mas não alcançou resultados, o que ele deve fazer, então? Resposta de aluno da zona urbana: "levar ela a um especialista";

Resposta de aluno da zona rural: "comprar uma puleiro com grade de ferro que caiba as galinhas e que os ovos passem por um tubo e que não quebre e que leve numa sesta de ovos".

A escolha de palavras como especialista, puleiro, sesta de ovos mostram que as marcas individuais e as determinadas pelo lugar social de onde procede o sujeito estarão presentes tanto na produção do texto como na leitura.

A análise da construção das respostas permitiu levantar um quadro de palavras e expressões usadas pelos alunos, sendo descartadas aquelas de uso muito corriqueiro (tem, vida, pessoas etc). 
Quadro 1 - Palavras e expressões usadas pelos alunos - $4^{\mathrm{a}}$ série

\begin{tabular}{|c|c|c|c|}
\hline Zona & Escola & Texto & Palavras e Expressões \\
\hline \multirow{6}{*}{ ZUC } & \multirow{3}{*}{ ZUC1 } & $\begin{array}{l}\text { Viciadas em comer os } \\
\text { próprios ovos. }\end{array}$ & Cultivar. \\
\hline & & $\begin{array}{l}\text { Pode me chamar de } \\
\text { Centro Cultural. }\end{array}$ & $\begin{array}{l}\text { Idosos, cartas, dá estudo, artes, } \\
\text { brincadeiras, emves (para "ao invés"), } \\
\text { jornais. }\end{array}$ \\
\hline & & $\begin{array}{l}\text { O tabaco consome } \\
\text { dinheiro público. }\end{array}$ & $\begin{array}{l}\text { Desenvolver, diminuir, elemento, enfarte, } \\
\text { ficiado (para "viciado"), droga, remédio, } \\
\text { sofre de cancer. }\end{array}$ \\
\hline & \multirow{3}{*}{ ZUC2 } & $\begin{array}{l}\text { Viciadas em comer os } \\
\text { próprios ovos. }\end{array}$ & $\begin{array}{l}\text { Natural, comilança, alimentos ingeridos, } \\
\text { substituilas, vacina, vitaminada, } \\
\text { fortificantes, cliente, esperiente, saldáveis, } \\
\text { diminuição. }\end{array}$ \\
\hline & & $\begin{array}{l}\text { Pode me chamar de } \\
\text { Centro Cultural. }\end{array}$ & $\begin{array}{l}\text { Loja de revista, jornais, eleitores (para } \\
\text { "leitores"), cidadão, notícias, } \\
\text { conscientizem, educação, cliente, } \\
\text { informativo, novidades, artes, coisas } \\
\text { culturais, gibis. }\end{array}$ \\
\hline & & $\begin{array}{l}\text { O tabaco consome } \\
\text { dinheiro público. }\end{array}$ & $\begin{array}{l}\text { Agressivo, fumança, lucro público, } \\
\text { adevertência, infelicidade, organismo, } \\
\text { drogas, progeto, energia, conceqüência, } \\
\text { contaminar, miséria, imposto, consiêncis, } \\
\text { lugares, produtor, agricultores. }\end{array}$ \\
\hline \multirow{6}{*}{ ZUB } & \multirow{3}{*}{ ZUB1 } & $\begin{array}{l}\text { Viciadas em comer os } \\
\text { próprios ovos. }\end{array}$ & $\begin{array}{l}\text { Saudável, medicamentos, remédio, lidar, } \\
\text { especialista, produtor, agricultores. }\end{array}$ \\
\hline & & $\begin{array}{l}\text { Pode me chamar de } \\
\text { Centro Cultural. }\end{array}$ & $\begin{array}{l}\text { Obras culturais, opçôes, cultura de leitura, } \\
\text { cultura brasileira, imaginaçôes, histórias } \\
\text { legal, povo. }\end{array}$ \\
\hline & & $\begin{array}{l}\text { O tabaco consome } \\
\text { dinheiro público. }\end{array}$ & $\begin{array}{l}\text { Pobresa, inssentivar, passo onestro (para } \\
\text { "honesto"), substancia, mobilizar, } \\
\text { vergonha, infarto do coração, maconbeiros, } \\
\text { drogas, açociedade (para "assossiação"), } \\
\text { justiça. }\end{array}$ \\
\hline & \multirow{3}{*}{ ZUB2 } & $\begin{array}{l}\text { Viciadas em comer os } \\
\text { próprios ovos. }\end{array}$ & $\begin{array}{l}\text { Acontecimento, prevenirem, vigiar, } \\
\text { sublimento (para "suplemento"), } \\
\text { comida, quiador (para "criador"), galias } \\
\text { (para "galinhas"). }\end{array}$ \\
\hline & & $\begin{array}{l}\text { Pode me chamar de } \\
\text { Centro Cultural. }\end{array}$ & $\begin{array}{l}\text { Exemplar, entretendimento (para } \\
\text { "entretenimento"), identificar. }\end{array}$ \\
\hline & & $\begin{array}{l}\text { O tabaco consome } \\
\text { dinheiro público. }\end{array}$ & $\begin{array}{l}\text { Anúncio de utilidade pública, } \\
\text { conscientizar, consideração, espensão (para } \\
\text { "expansão"), população, disperdiciado. }\end{array}$ \\
\hline
\end{tabular}




\begin{tabular}{|c|c|c|c|}
\hline & \multirow{3}{*}{ EP } & $\begin{array}{l}\text { Viciadas em comer os } \\
\text { próprios ovos. }\end{array}$ & $\begin{array}{l}\text { Dar continuidade as espécies, experiência, } \\
\text { previnam-se, sugestões, desacostumam, } \\
\text { atentem-se, fazendeiros, veterinário, } \\
\text { especialista, providência. }\end{array}$ \\
\hline & & $\begin{array}{l}\text { Pode me chamar de } \\
\text { Centro Cultural. }\end{array}$ & $\begin{array}{l}\text { Clientes, jornais, população brasileira, } \\
\text { educativos, transmitir cultura. }\end{array}$ \\
\hline & & $\begin{array}{l}\text { O tabaco consome } \\
\text { dinheiro público. }\end{array}$ & $\begin{array}{l}\text { Fase, sustentar, futuro, empobrecem, } \\
\text { felicidade, usuários, insentivar, investir. }\end{array}$ \\
\hline \multirow{12}{*}{ ZR } & \multirow{3}{*}{ ZR1 } & $\begin{array}{l}\text { Viciadas em comer os } \\
\text { próprios ovos. }\end{array}$ & $\begin{array}{l}\text { Venenos, chocar, comedora, produção de } \\
\text { ovos. }\end{array}$ \\
\hline & & $\begin{array}{l}\text { Pode me chamar de } \\
\text { Centro Cultural. }\end{array}$ & $\begin{array}{l}\text { Gibis, movimentada, aventura, coisas } \\
\text { culturais, cultura brasileira. }\end{array}$ \\
\hline & & $\begin{array}{l}\text { O tabaco consome } \\
\text { dinheiro público. }\end{array}$ & $\begin{array}{l}\text { Irresponsáveis, prejuisa (verbo } \\
\text { "prejuisar" (?)), cancer. }\end{array}$ \\
\hline & \multirow{3}{*}{ ZR2 } & $\begin{array}{l}\text { Viciadas em comer os } \\
\text { próprios ovos. }\end{array}$ & $\begin{array}{l}\text { Estados, afinada (para "afiada"), } \\
\text { pintinho, energia, chocar, desverminar, } \\
\text { obrigaçâo, filbotes, lidar. }\end{array}$ \\
\hline & & $\begin{array}{l}\text { Pode me chamar de } \\
\text { Centro Cultural. }\end{array}$ & $\begin{array}{l}\text { Povo, culturalidade, entendimento (para } \\
\text { "entretenimento"), livros culturais, } \\
\text { jornais, sabedoria. }\end{array}$ \\
\hline & & $\begin{array}{l}\text { O tabaco consome } \\
\text { dinheiro público. }\end{array}$ & $\begin{array}{l}\text { Estufas de fumo, população, ponbarem, } \\
\text { conciência, município, drogas, prejudicar. }\end{array}$ \\
\hline & \multirow[b]{3}{*}{ ZR3 } & $\begin{array}{l}\text { Viciadas em comer os } \\
\text { próprios ovos. }\end{array}$ & $\begin{array}{l}\text { Não carece, choca, ovo de plástico, ponhar, } \\
\text { vacinar, reprodução, granjas, previnir. }\end{array}$ \\
\hline & & $\begin{array}{l}\text { Pode me chamar de } \\
\text { Centro Cultural. }\end{array}$ & $\begin{array}{l}\text { Gibis, passatempos, tranquila, noticia, } \\
\text { acontecimento, entupido de revistas, } \\
\text { assuntos culturais, reportagens, negócio. }\end{array}$ \\
\hline & & $\begin{array}{l}\text { O tabaco consome } \\
\text { dinheiro público. }\end{array}$ & $\begin{array}{l}\text { Nicotina, plantadores de fumo, passaporte } \\
\text { da morte, câncer nos pulmões, epotência } \\
\text { sexual, desenvolvimento, sociaçãa (para } \\
\text { "associação"), aproximadamente, objeto, } \\
\text { avissia (para "vicia"), imposto, veneno, } \\
\text { porcaria, pensamento, maluqueiro. }\end{array}$ \\
\hline & \multirow{3}{*}{ ZR4 } & $\begin{array}{l}\text { Viciadas em comer os } \\
\text { próprios ovos. }\end{array}$ & $\begin{array}{l}\text { Volume de ovos, orientacãa, puleiro, sesta } \\
\text { de ovos, desenvolvimento. }\end{array}$ \\
\hline & & $\begin{array}{l}\text { Pode me chamar de } \\
\text { Centro Cultural. }\end{array}$ & Noticias. \\
\hline & & $\begin{array}{l}\text { O tabaco consome } \\
\text { dinheiro público. }\end{array}$ & $\begin{array}{l}\text { Sofrer do coração, átona (para “à toa"), } \\
\text { preservem, sobreviver, etocafica (para } \\
\text { "intoxica"), sofrimento de câncer. }\end{array}$ \\
\hline
\end{tabular}

Dessa forma, para a leitura do texto "Viciadas em comer os próprios ovos", surgiram, nas escolas de zona rural, palavras e expressões próprias desse meio social: desverminar, pintinho, choca, granjas, puleiro, venenos. Já entre os alunos da zona urbana, foram comuns palavras como: cultivar, experiente, especialista, veterinário, fazendeiro. 
$\mathrm{Na}$ construção das respostas referentes ao texto "Pode me chamar de Centro Cultural", pôde-se constatar, nos alunos do meio urbano, o emprego de palavras como: cidadão, clientes, educação, educativa, exemplar, informativo. A palavra "cultura" foi utilizada com bastante frequência. Os alunos do meio rural raramente empregaram essa palavra.

$\mathrm{Na}$ leitura do texto "O tabaco consome dinheiro público", verificou-se um repertório vocabular mais amplo e diversificado em quase todas as escolas, certamente porque a temática é bastante discutida na mídia televisiva. Expressões como enfarte do coração, consciência, drogas, câncer foram constantemente utilizadas pelos alunos. Também, algumas palavras revelam a concepção que esses sujeitos têm a respeito do cigarro e do usuário dessa droga: maluqueiras, maconbeiros, porcaria, irresponsáveis. Os alunos da zona rural trouxeram, novamente, suas experiências vivenciais. Muitos deles são filhos de pessoas que se dedicam à cultura do fumo. Assim, surgiram expressões como: plantadores de fumo, estufas de fumo, veneno (no sentido de "agrotóxico"). Ainda, construções como avissia, não carece, ponhar - empregadas por muitos alunos da zona rural - evidenciam a variedade linguística utilizada por eles.

Entretanto, apesar de muitos alunos adotarem uma atitude questionadora e revelarem suas experiências vivenciais, constatou-se que a maioria apresenta muitas dificuldades na interação com o texto.

Doravante, aponta-se e discute-se uma série de explicações levantadas no decorrer da pesquisa para as dificuldades de compreensão dos sujeitos-leitores do $2^{\circ}$ ciclo do ensino fundamental, as quais podem ser o ponto de partida para reflexões acerca da qualidade de leitura desses sujeitos.

A primeira explicação levantada é:

Explicação 1: A pesquisa detectou que a maioria das escolas tem trabalhado o texto como um produto estático, sem história, isto é, independente de para quem se fala e para que se fala.

Observem-se estes exemplos: 
- Considerando que o texto foi produzido pelo Ministério da saúde, com que objetivo esse texto foi escrito? (Texto: "O tabaco consome dinheiro público") Respostas: "é um passo importante para criar uma sociedade mais justa"; "com o tabaco".

- A quem é destinado esse texto? (Texto: "Viciadas em comer os próprios ovos").

Resposta: "às galinhas "

As respostas dadas por muitos alunos revelam que eles não conseguem recuperar no texto os indícios textuais que os ajudariam a perceber o tipo de interação proposta pelo autor, nem conseguem identificar um possível leitor para o texto. Quando os alunos mostram dificuldades para atribuir um objetivo e um possível destinatário, faltamlhes noções básicas sobre o escrito: o conhecimento da situação comunicativa. De acordo com Colomer \& Camps,

[...] na comunicação diferida, o leitor tem de aprender a contextualizar o texto a partir dos elementos presentes no escrito: terá de entender o tipo de interação social propostapelo escritor (que objetivo tem a comunicação, em que lugar e tempo se produs, que relação reflete o registro linguistico de que se utiliza, etc.) como também terá de contrastar sua própria finalidade de leitura, que pode coincidir em maior ou menor gran com a do escritor. (2002, p. 49)

Em outras palavras, a ausência do conhecimento da situação comunicativa dificulta a interação texto-leitor, constituindo-se num entrave para a construção dos sentidos.

Observa-se, em algumas respostas, que há alunos que têm conhecimento de que o texto objetiva um tipo de comunicação, mas eles acreditam que a interação é a mesma, seja qual for o gênero textual. Os exemplos a seguir mostram que vários alunos consideram que a finalidade de qualquer texto é informar, apenas, de maneira generalizante:

"esse texto ajuda a ensinar as pessoas" (ZR1); "com que a gente aprenda e conheça os tipos das aves" (ZUB1); "de aprender" (ZUC2) respostas à questão "Com que objetivo esse texto foi escrito?" (Viciadas em comer os próprios ovos); 
"o objetivo é explicar a cultura" (ZR1); "levar a leitura para todos" (ZUC1); "para mostrar mais um pouco como a revista é importante" (ZUB1) - respostas à questão "Considerando que o texto foi produzido pela ANER, qual o objetivo do texto?” (Pode me chamar de Centro Cultural);

"para deixar as pessoas mais informadas" (ZR1); "que as pessoas gravem o que é tabaco " (ZUC2); - resposta à questão "Considerando que o texto foi produzido pelo Ministério da Saúde, com que objetivo esse texto foi escrito?” (O tabaco consome dinheiro público).

Aqui, surge outra explicação para o problema:

Explicação 2: Constatou-se que os programas escolares têm ignorado a diversidade de gêneros textuais, trabalhando exclusivamente com os textos de caráter referencial ou a escola tem exposto os alunos ao contato com a diversidade textual, mas têm dado o mesmo tratamento didático para diferentes géneros.

O problema é mais evidente na leitura do texto "Pode me chamar de Centro Cultural". Apenas 12\% do total perceberam a intenção persuasiva da propaganda publicitária. Dessa forma, os alunos, ao lerem o texto, mostraram-se leitores ingênuos, que não percebem os mecanismos apelativos destinados a seduzir o leitor e provocar-lhe determinado comportamento, neste caso, trazê-lo para a banca e persuadi-lo a comprar revistas, evidenciando a falta de tratamento com textos sociais como esse.

Para a leitura do texto "O tabaco consome dinheiro público", também persuasivo, a postura foi diferenciada. Neste, os alunos atingiram o índice de $50 \%$ de acertos. O texto trata de uma temática de grande circulação social: diversas propagandas destinadas a combater o tabagismo circulam na mídia (principalmente na TV, em jornais e revistas), nos murais das escolas, nos livros didáticos. Dessa forma, para a maioria não se tornou difícil adiantar que um texto sobre tabaco tem o objetivo de "fazer as pessoas pararem de fumar" - resposta dada por grande parte dos alunos. 
Outro problema evidenciado refere-se à dificuldade de leitura dos enunciados das questões. Algumas respostas inadequadas, referentes às perguntas que abordam objetivo e destinatário, foram dadas a perguntas semelhantes a estas: "Sobre o que trata o texto?"; "Qual o título do texto?"; "Quem escreveu o texto?".

Assim, levanta-se uma terceira explicação:

Explicação 3: Os dados analisados permitem inferir que a escola tem submetido os alunos a uma mesma tipologia de perguntas sempre.

Os exemplos a seguir confirmam que os alunos internalizaram determinados enunciados e por isso têm dificuldades quando se deparam com outros tipos de perguntas:

Texto: "Viciadas em comer os próprios ovos" Questão: Com que objetivo esse texto foi escrito? Respostas que atenderiam à pergunta "Sobre o que trata o texto?": "sobre as galinhas"; "de venenos e outros"; "que as galinhas estavam comendo os próprios ovos" (ZR1); "com objetivo da galinha com os ovos"; "sobre os ovos" (ZUB2);

Resposta que atenderia à pergunta "Quem escreveu o texto?": "esse texto foi escrito por uma criadora de galinha chamada Maria Virginia Franco" (ZR1); "Maria Virginia" (ZUB2);

Questão: A quem é destinado esse texto?

Respostas que atenderiam à pergunta "Sobre o que fala o texto?": "esse texto fala sobre a criação de galinhas" (ZR1); "as galinhas"(ZUB2); "édestinado sobre as galinhas e os ovos"(ZUC2); Respostas que atenderiam à pergunta "Qual o título do texto?": "viciadas em comer os próprios ovos" (ZR1, ZUC1).

Essa postura de ensino - apresentar ao aluno uma mesma tipologia de questões - aproxima-se das "fórmulas de inteligibilidade" descritas por Leffa $(1999$, p. 17). As fórmulas de inteligibilidade consistem no uso, somente, de estruturas conhecidas pelos alunos, sem 
oferecer-lhes qualquer desafio, pois se acredita que, expô-los a uma situação estranha, pode causar dificuldades na compreensão e impedir a leitura.

Evidencia-se, aí, a ênfase no processamento linear da leitura, na concepção de leitura como extração de significados do texto, além do processamento de atribuição, que será discutido a seguir.

Ainda, sobre os enunciados, surge outra explicação:

Explicação 4: Pôde-se perceber que as perguntas de compreensão nas aulas de leitura têm ensinado o aluno a apenas decodificar, isto é, encontrar no texto trechos que repitam as palavras já decodificadas na pergunta.

Citam-se como exemplos as seguintes situações referentes à leitura do texto "O tabaco consome dinheiro público":

Pergunta: "No último parágrafo do texto, está escrito "É um passo importante para criar uma sociedade mais justa". Que passo é esse?"

Resposta: "para desenvolver uma sociedade mais justa"(ZUC1; ZR2); "é importante criar uma sociedade mais justa" (ZUB1)

Pergunta: "Por que a dependência do cigarro aumenta as desigualdades sociais"?

Resposta: "desigualdades sociais muitos trabalhadores fumantes além de perderem a saúde gastam com cigarros o que poderia ser usado em alimentação e educaşão" (ZR2); "a dependência do tabaco também aumenta as desigualdades sociais gastão de cigarros" (ZUC1); "gastam com cigarro e que poderia ser usado em alimentação e educaşão" (ZUB1).

Nesses casos, a leitura do texto tornou-se dispensável. Bastou ao aluno passar os olhos pelo texto, encontrar nele a forma gráfica da pergunta e reproduzir o trecho na resposta, reforçando-se, mais uma vez, a atitude passiva diante do texto e a ênfase no processamento unidimensional da leitura.

Uma outra explicação a ser levantada é: 
Explicação 5: Algumas escolas têm formado leitores atribuidores, isto é, leitores que procuram adivinhar as respostas, sem procurar confirmá-las no texto.

Retomando-se Kleiman:

Ir ao texto com idéias pré-concebidas, inalteráveis, com crenças imutáveis dificulta a compreensão quando estas não correspondem àquelas que o autor apresenta, pois nesse caso o leitor nem sequer consegue reconstruir o quadro referencial através das pistas formais. (2000, p. 65)

Assim, além do processamento da extração, evidenciado na explicação 3, constatou-se que vários alunos tomaram conhecimento do assunto, acionaram os esquemas pertinentes e deram respostas de acordo com as suas experiências vivenciais. $\mathrm{Na}$ leitura do texto "O tabaco consome dinheiro público", vários alunos deram respostas semelhantes para a pergunta "Considerando que o texto foi produzido pelo Ministério da Saúde, com que objetivo esse texto foi escrito?":

"para que as pessoas parem de fumar porque isso traz muitas doenças no pulmão "(EP);

"em objetivo de ninguém comprar tabaco por que causa infarto do coração "(ZUB1);

"o ministério da saúde quer acabar com isso de ficarem vendendo tabaco.

E quem vende tabaco para menor de 18 anos corre o risco de ser preso".

As informações destacadas não estão presentes no texto, foram trazidas pelos alunos a partir de suas experiências prévias de leitura da mesma temática, na mídia. Assim, "o que o texto faz, portanto, não é apresentar um novo sentido ao leitor, mas fazê-lo buscar, dentro de sua memória, um sentido que já existe, que já foi de certa maneira construído previamente" (LEFFA, 1999, p. 24).

Como a maioria já foi ao texto com idéias pré-concebidas, tornou-se difícil perceber que, com a campanha, o Ministério da Saúde também tem como objetivo diminuir os gastos para tratar os graves danos causados pelo tabagismo, comprovando que os alunos fizeram mais uso das suas experiências de leitura prévia do que das informações visuais do texto. 
Quando o aluno está preso a formulações prévias, ele mostra dificuldades em realizar inferências de ligação textual e inferências extratextuais (ABARCA; RICO, 2003).

Retome-se o texto "Viciadas em comer os próprios ovos",

(1) Por que algumas galinhas comem os ovos logo após a postura? (2) Como impedir que elas façam isso?

(3) Esse é um problema que costuma ocorrer com algumas aves e que, infelizmente, não é muito fácil de ser resolvido. (4) A primeira coisa a ser considerada é a carência de cálcio e de proteínas, que geralmente ocorre quando a dieta das aves é composta apenas por milho.

Para responder as questões - "O fato de as galinhas comerem os próprios ovos pode ter alguma coisa a ver com a alimentação? Explique"; "A que se deve a carência de cálcio e proteína nas galinhas?" - o aluno deveria estabelecer dois tipos de inferências;

$1^{\circ}$ ) realizar uma inferência de ligação textual entre as frases 1 e 4 para compreender que o fato de as galinhas comerem os próprios ovos tem como uma das causas a carência de cálcio e proteínas. Por sua vez, a carência de cálcio e proteínas tem como causa a dieta composta apenas por milho -relação que se estabelece mediante uma nova inferência de ligação textual. Essa inferência torna-se mais fácil de ser realizada do que a primeira, pois as idéias são sucessivas, muito próximas;

$2^{\circ}$ ) acionar seu conhecimento de mundo para compreender que cálcio e proteínas são substâncias presentes nos alimentos ou inferir a partir da informação subseqüente "que geralmente ocorre quando a dieta das aves é composta apenas por milho".

Os alunos que não perceberam essas relações processaram as frases como dados desconexos e isolados e tiveram dificuldades para responder as questões. Exemplos:

"O fato de as galinhas comerem os próprios ovos pode ter alguma coisa a ver com a alimentação? Explique." "esse é um problema ocorre com alguma aves e que, infeliżmente, não é muito fácil 
de ser resolvido" (ZR1); "não porque ela sempre come bem "(ZUB1);

"nãoporque não tem nada a ver" (ZR2).

Vários alunos não estabeleceram as conexões textuais apropriadas e aportaram-se excessivamente às suas hipóteses para adivinhar a resposta:

"eu acho que é alguma alimentação que contém o gosto de um ovo assim as galinhas sentem o cheiro do ovo e bicam" (ZUC1);

"sim: porque ela fica com fome e ai ela come o seu próprio ovo "(ZR2).

Discutem-se, também, as inferências a partir das respostas à pergunta "Não importa qual sua idade ou gosto, aqui a informação e a diversão estão garantidas. Por quê?" - do texto "Pode me chamar de Centro Cultural".

Pode me chamar de Centro Cultural.

(1) Não importa qual a sua idade on gosto, aqui a informação e a diversão estão garantidas. (2) São mais de 1500 titulos trazendo cultura, lazer e entretenimento em cada uma das 32 mil bancas de revistas espalhadas pelo Brasil.

Observam-se, na escrita dos alunos, as seguintes situações:

- respostas em que se evidenciam inferências de ligação textual: "porque são mais de 1500 titulos trazendo cultura, lazer e entretenimento em cada uma das 32 mil bancas de revistas espalhadas pelo Brasil". Neste caso, os alunos realizaram uma leitura ascendente, pois não possuem conhecimentos de mundo suficientes para atribuir sentidos ao texto. Foi o que aconteceu nas respostas dadas por grande parte dos alunos de ZR4;

- respostas em que se evidenciam inferências extratextuais não apropriadas: "porque tem vita [fita] de vídeo gueime e outros filmes legais" (ZUC2). Neste caso, os alunos realizaram uma leitura excessivamente descendente, não tendo realizado o processamento ascendente para verificar a leitura; respostas em que se evidenciam inferências extratextuais apropriadas: "porque lá tem revistas em quadrinhos e noticias" (ZR2). Neste caso, estabeleceu-se interação entre o texto e os conhecimentos do leitor: 
diversão $\rightarrow$ revistas em quadrinhos

informação $\rightarrow$ notícias;

- respostas em que não há inferências, pois o aluno não apresenta novas informações. Reproduz apenas as palavras decodificadas na pergunta: "porque tem informação e diversão"; "porque não importa o gosto portanto que tenha informação e diversão "(ZUB2).

Há, ainda, uma outra explicação para as dificuldades de leitura dos alunos:

Explicação 6: A pesquisa demonstra que há nas escolas uma confluência de concepções de leitura, visto que, muitas vezes, um mesmo aluno para a leitura de um mesmo texto ora toma o texto como única fonte de informação ora despreza-o totalmente e responde às perguntas baseando-se, exclusivamente, em adivinhações.

Observa-se, nos exemplos, que o mesmo aluno, para responder uma pergunta referente ao texto "O tabaco consome dinheiro público", copia partes do texto, e para responder outra, recorre somente ao seu repertório de conhecimentos prévios:

Pergunta: "Considerando que o texto foi produzido pelo Ministério da Saúde, com que objetivo esse texto foi escrito?" Resposta: "em objetivo de ninguém comprar tabaco por que causa infarto do coração";

Pergunta: "Por que a dependência do tabaco aumenta as desigualdades sociais?"

Resposta: "as desigualdades sociais porque muitos trabalhadores fumantes além de perderem a saúde gastam com cigarros o que poderia ser usado na alimentação e educação" (ZUB1);

Pergunta: "Explique com suas palavras o título do texto." Resposta: "Bilhões de reais saem do bolso do contribuintepara tratar a dependência do tabaco e as graves doenças que ele causa "; Pergunta: "De acordo com o texto, somente quem utiliza tabaco sofre prejuízos? Explique:" 
Resposta: "Não também quem está perto de um fumante quem sente toda a fumasa indo nariz, dele ou dela" (ZUC2);

Pergunta: "De acordo com o texto, somente quem utiliza tabaco sofre prejuízos? Explique:"

Resposta: "Quem não fuma pode viver até 10 anos mais do que um fumante";

Pergunta: "Por que a dependência do tabaco aumenta as desigualdades sociais?"

Resposta: "porque muitos trabalhadores fumantes além de perderem a saúde gastam com cigarros" (ZR1)

Sobre essa relação, Silva afirma que

as nossas concepç̃es dos fenômenos, dos processos, dos objetos existentes no mundo afetam diretamente as nossas práticas sociais. Assim, aquilo que sei ou penso que sei sobre o ato de ler ou, ainda, a forma pela qual eu concebo ou leio a leitura enriquece ou empobrece, dinamiza ou paralisa, dirige ou desvia, conscientiza ou serve para alienar as ações relacionadas com a formação de leitores [...] Possuimos explícita - ou implicitamente, uma definição do 'ler' em função de uma prática que executamos, de experiências vividas em sociedade. (1995, p. 47)

Percebe-se, assim, que as escolas não trabalham com uma concepção definida de leitura, mas sim com várias concepções ao mesmo tempo, o que impede que os alunos expressem com segurança o que compreendem pelo ato de ler. Suspeita-se que isso se deva à ausência de discussões sobre o processo de leitura na formação acadêmica dos professores.

\section{Considerações finais}

Constatou-se que um percentual mínimo de alunos concebe o ato da leitura como uma oportunidade de interagir com o texto. Os resultados da pesquisa demonstraram que a maioria dos leitores do final do segundo ciclo do Ensino Fundamental apresenta: 
a) muitas dificuldades de ler, visto que não reconhece as funções pragmáticas do texto (que o texto é escrito para um leitor e com alguma finalidade);

b) não compreende o enunciado das questões, ignorando certas informações textuais imprescindíveis para a compreensão;

c) diante das tarefas de leitura, o aluno toma o texto como fonte única de informação e, assim, executa as tarefas de leitura copiando informações do texto, mesmo que essas não sejam condizentes com a pergunta realizada;

d) outros alunos se mostram como leitores "adivinhadores", já que confiam exageradamente em suas próprias predições, sem procurar confirmá-las através de uma leitura ascendente; e) outros, ainda, apresentam uma confluência de concepções, pois ora utilizam o procedimento de extração, ora o de atribuição.

Em todas as escolas, identificam-se alunos que interagem, "adivinham" e extraem, ou, ainda, alunos que ora extraem ora adivinham. Entretanto, uma dessas concepções sobressai-se, conforme aponta o levantamento a seguir:

- alunos que interagem com o texto são constatados em maior número nas escolas EP e ZUC2;

- alunos extratores encontram-se predominantemente nas escolas ZUC1, ZUB2, ZR1, ZR3, ZR4;

- alunos "adivinhadores" aparecem em maior número em ZR2;

- alunos que apresentam confluência de concepções são encontrados em ZUB 1.

Por fim, a partir dos dados analisados, é possível constatar que:

a) os alunos da $4^{a}$ série investigados vêem na leitura uma possibilidade de constituir-se, de revelar-se, de mostrar desejos e visões de mundo;

b) a escolha de palavras, nas respostas escritas, mostram que as marcas individuais e as determinadas pelo lugar social de onde procede o aluno estarão presentes tanto na produção do texto como na leitura; 
c) a maioria dos alunos apresenta muitas dificuldades na interação com o texto;

d) quando os alunos mostram dificuldades para atribuir um objetivo e um possível destinatário, faltam-lhes noções básicas sobre o escrito: o conhecimento da situação comunicativa; e) a falta de tratamento com textos sociais, como a propaganda, é comum nas leituras apresentadas;

f) vários alunos tomaram conhecimento do assunto dos textos, acionaram os esquemas pertinentes e deram respostas de acordo com as suas experiências vivenciais.

Para cumprir uma das tarefas da pesquisa educacional brasileira, os resultados deste estudo estão sendo discutidos com professores da rede municipal e estadual de ensino da região de IratiPR, ern encontros promovidos pela Secretaria Municipal de ESucação e pelo Núcleo Regional de Ensino. Acredita-se, assim, na contribuição para a melhoria da qualidade de leitura dos alunos do ensino fundamental atendidos no Município de Irati-PR, pretendendo, futuramente, que essas contribuições se estendam ao restante do sistema educacional paranaense.

\section{Referências}

ABARCA, E. V.; RICO, G. M. Por que os textos são tão difíceis de compreender? As inferências são a resposta. In: TEBEROSKY, A. (Org.). Compreensão na leitura: a língua como procedimento. Trad. Fátima Murad. Porto Alegre: Artmed, 2003. p. 139-153.

COLOMER, T.; CAMPS, A. Ensinar a ler, ensinar a compreender. Trad. Fátima Murad. Porto Alegre: Artmed, 2002.

DELL'ISOLA, R. L. P. A interação sujeito-linguagem em leitura. In: MAGALHÃES, I. (Org.). As múltiplas faces da linguagem. Brasília: UNB, 1996. p. 69-75.

GOODMAN, K. S. O processo da leitura: considerações a respeito das línguas e do desenvolvimento. In: FERREIRO, E; PALÁCIO, M, 
G (Orgs.). Osprocessos de leitura e escrita: novas perspectivas. Porto Alegre: Artes Médicas, 1987. p. 11-22.

KATO, M. A. No mundo da escrita: uma perspectiva psicolinguística. São Paulo: Ática, 1986.

KLEEVIAN, A. Texto e leitor: aspectos cognitivos da leitura. 7. ed. Campinas: Pontes, 2000.

Leitura: ensino e pesquisa. Campinas: Pontes, 1989.

LEFFA, V. J. Perspectivas no estudo da leitura: texto, leitor e interação social. In: LEFFA, Vilson J.; PEREIRA, Aracy E. (Orgs.). O ensino da leitura e produção textual. Pelotas: Educat, 1999. In: LEFFA, Vilson J. (Compilador). TELA (Textos em Linguistica Aplicada). Pelotas: Educat, 2000. CD-Rom.

ORLANDI, E. P. Análise de discurso: princípios e procedimentos. Campinas: Pontes, 2000.

SILVA, E. T. Leitura na escola e na biblioteca. Campinas: Papirus, 1995.

SMITH, F. Leitura significativa. Trad. Beatriz Affonso Neves. Porto Alegre: Artmed, 1999.

SOLE, I. Ler, leitura, compreensão: "sempre falamos a mesma coisa?". In: TEBEROSKY, A. (Org.). Compreensão na leitura: a língua como procedimento. Trad. Fátima Murad. Porto Alegre: Artmed, 2003. p. $17-34$. 